\title{
Clinical Study of Patients with Heart Failure under treatment with Ozone Therapy
}

\author{
Javier Cespedes-Suarez, Yanisley Martin-Serrano, Maria Rosa Carballosa-Peña, Diana Rosa Dager- \\ Carballosa
}

Cardiozono Medical Center, Luanda, Angola

\section{(2) OPEN ACCESS}

\section{Citation \\ Cespedes-Suarez J, Martin-Serrano Y, Carballosa-Peña MR, Dager-Carballosa DR. Clinical Study of Patients with Heart Failure under treatment with Ozone Therapy. J Ozone Ther. 2019:2(3) \\ doi: 10.7203/jo3t.2.3.2018.11461}

\section{Academic Editor \\ Jose Baeza-Noci, \\ School of Medicine, Valencia University, SPAIN}

\section{Editor}

World Federation of Ozone Therapy, Bologna, ITALY

\section{Received}

February 1, 2018

\section{Accepted}

February 14, 2018

\section{Published}

December 15, 2018

\section{Intellectual Property}

Cespedes-Suarez J.

This is an open access article distributed under the terms of the Creative Commons Attribution License (CC BY 4.0), which permits unrestricted use, distribution, and reproduction in any medium, provided the original author and source are credited.

\section{Author Information}

docj09@gmail.com

\section{ABSTRACT}

Heart failure (HF) is framed in one of the types of cardiovascular diseases; it consists of an acute and chronic form. The disease can evolve slowly from asymptomatic left ventricular dysfunction, to a state of severe disability, presenting a wide prevalence in the population around $10 \%$ in people over 70 years old. More than three-quarters of the deaths from this pathology normally occur in low or middle-income countries. Angola is not exempt from this health problem be observed in a relatively young people, bringing disability and death at an early stage of life. Scientific advances and innovative treatments for the control and prevention of the disease continue to be insufficient.

The ozone for it's antioxidant, hemorehological properties, oxygenation enhancers and blood circulation is an alternative treatment for these patients.

We have performed a study where 45 patients who were diagnosed with a chronic stage of II-III HF due to the functional classification of the New York Heart Association (NYHA) and American Cardiology College / American Heart Association (ACC / AHA), previous echocardiogram with a Fracture of Left Ventricular Ejection (LVEF) less than $45 \%$. We administered a Major Autohemotherapy with a protocol of 15 sessions, maintenance every 15 days and cycles every 6 months at $50 \mu \mathrm{g}$ of concentration, an initial dose of $4,000 \mu \mathrm{g} / \mathrm{mL}$ up to $12,000 \mu \mathrm{g} / \mathrm{mL}$ during the 3 years of treatment.

Patients after the first treatment cycle improve their functional physical capacity and LVEF increased to normal levels (55\%). It was proved that Autohemotherapy is an adjuvant, viable and beneficial treatment in chronic HF.

Keywords: Heart failure, major autohemotherapy, ozone therapy, left ventricular ejection fraction

\section{Introduction}

Heart failure (HF) is a worldwide public health problem in developed countries, approximately $2 \%$ of the adult population has HF, a prevalence that increases exponentially with age, as it is less than $1 \%$ before the 50 years and then doubles with each decade to exceed $8 \%$ among those over 75 years $[1,2]$. 
$\mathrm{HF}$ is the inability of the heart to pump blood properly according to the needs of the hepatic metabolism; if it succeeds, it does so at the expense of an abnormal elevation of the filling pressure of the cardiac ventricles either by myocardial disease or excessive overload. This brings with it a neurohormonal response with effort intolerance, fluid retention and reduced longevity.

In 2003, the American Heart Association (AHA) reported that 48 million hospital discharges occurred in the United States with this diagnosis [3]. In the Framingham study, HF in men aged 50-59 years was 8 per 1,000 inhabitants and increasing to 70 per 1,000 in patients over 80 years (very similar numbers in women) [4].

However, in Africa it has a rather different etiology to that described in Europe and America, it is related to the degree of development of the continent and affects predominantly a young population. Damasceno, in his study on heart failure in Africa, throughout a meta-analysis including studies published up to 2007 by Bongani Mayosi et al. [5] found that arterial hypertension was the main cause of heart failure followed by cardiomyopathies.

The current therapeutic approach of patients with HF is aimed at improving signs and symptoms, correcting volume overload, increasing end-organ perfusion, improving cardiac contractility and hemodynamic status [6].

During the last 24 years, the mechanisms of action of ozone in human blood have been clarified [7]. It is stated that its therapeutic properties are: improving the metabolism of oxygen, modulate biological oxidative stress, modulate the immune system, intervene in the synthesis and / or release of autacoids (endogenous substances with diverse actions physiological and pharmacological), regulate metabolism, in addition to exert a great effect as germicide [8].

For all of the above, our team decided to analyze the clinical and echocardiographic (LVEF) effects induced by major autohemotherapy applied in patients with CHF.

\section{Materials and methods}

A retrospective cross-sectional study was performed at the Cardiozono Medical Center located in Luanda, Angola. The final sample consisted of 45 patients of both sexes, who presented a diagnosis of CHF, referred from our Cardiology Department and other Hospital offices, who started treatment of ozone therapy indistinctly in the period from June 2014 to June 2017. We emphasize that in our work we performed an analysis of the patients treated in this time period of their evolution corresponding to one year performing the therapy.

\section{Inclusion criteria were:}

Patients with a diagnosis of HFC class II-III of the New York Heart Association (NYHA) [9] and American Cardiology College / American Heart Association (ACC / AHA), previous echocardiography with a (LVEF) between $35 \%$ and $50 \%$ and patients with a time greater than 6 months of treatment with furosemide $40 \mathrm{mg}$ at 8 hours and $40 \mathrm{mg}$ at 16 hours, spironolactone 50 mg every 12 hours, hydrochlorothiazide $25 \mathrm{mg}$ daily, carvedilol $12.5 \mathrm{mg}$ every 12 hours, mononitrate of isosorbide $20 \mathrm{mg}$ daily and aspirin $100 \mathrm{mg}$ daily. During the period of time analyzed. 45 patients were included in the 
treatment, 20 were women and 25 men, the age of the patients was from 40 to 65 years, (60 to 65 years, 20 patients, 11 women and 9 men, from 50 to 59 years, 20 patients, 13 men and 7 women and from 40 to 49 years old, 5 patients, 3 men and 2 women).

\section{Exclusion criteria were:}

Patients with HF of a diagnosis (less than 6 months) with medical treatment and patients with secondary HF produced by autoimmune diseases.

\section{Treatment Protocol:}

The patients received 15 sessions of major autohemotherapy (one daily session). In each session we used a German-made Promedic Humazon equipment (Humares $\mathrm{GmbH}$, Bruchsal, Germany), 3-way stopcock, epicranial needle $19 \mathrm{G}$, Sangiset (Humares $\mathrm{GmbH}$, Bruchsal, Germany) with capacity of $350 \mathrm{~mL}$ where we put $10 \mathrm{~mL}$ of $3.13 \%$ sodium citrate to avoid blood clot during the procedure and other disposable material.

The major autohemotherapy (Table 1) was performed at a concentration of $50 \mu \mathrm{g} / \mathrm{mL}$ in $100 \mathrm{~m}$ of blood; the initial dose of the therapy was $4000 \mu \mathrm{g}$ (80 $\mathrm{mL}$ of ozone gas at $50 \mu \mathrm{g} / \mathrm{mL}$ concentration); we increased the dose by $2000 \mu \mathrm{g}$ every 2 days until reaching a dose of $12000 \mu \mathrm{g}(240 \mathrm{~mL}$ of ozone gas at $50 \mu \mathrm{g} / \mathrm{mL}$ concentration), maintaining this dose as a maintenance dose every 15 days throughout the year.

Table 1: Ozone Treatment protocol

Days of treatment

Days 1-2

Days 3-4

Days 5-6

Days 7-8

Days $9-15$

Maintenance every 15 days
Amount of $\mathrm{O}_{3}(\mu \mathrm{g})$

(4000) $\mu \mathrm{g}$ per $100 \mathrm{~mL}, 50 \mu \mathrm{g} / \mathrm{mL}$

(6000) $\mu \mathrm{g}$ per $100 \mathrm{~mL}, 50 \mu \mathrm{g} / \mathrm{mL}$

(8000) $\mu \mathrm{g}$ per $100 \mathrm{~mL}, 50 \mu \mathrm{g} / \mathrm{mL}$

(10000) $\mu \mathrm{g}$ per $100 \mathrm{~mL}, 50 \mu \mathrm{g} / \mathrm{mL}$

(12000) $\mu \mathrm{g}$ per $100 \mathrm{~mL}, 50 \mu \mathrm{g} / \mathrm{mL}$

(12000) $\mu \mathrm{g}$ per $100 \mathrm{~mL}, 50 \mu \mathrm{g} / \mathrm{mL}$

The parameters evaluated were:

- Heart failure Functional Classification according NYHA [9] (New York Heart Association) (Table 2)

- Ejection Fraction Classification according NYHA [9]:

- Ejection fraction NORMAL $\approx 50-70 \%$ is expelled during each contraction (there is usually a sense of comfort during physical activities)

- Ejection fraction LIMIT $\approx 41-49 \%$ is expelled during each contraction (symptoms may be more noticeable during physical activity)

- Reduced ejection fraction $\leq 40 \%$ is expelled during each contraction (symptoms may be more noticeable at rest) 
Tabla 2. Functional Classification of NYHA (New York Heart Association) HF.

\begin{tabular}{|l|l|l|}
\hline CLASS & CHARACTERÍSTICS & DEFINITIÓN \\
\hline I & $\begin{array}{l}\text { Without limitation: normal physical } \\
\text { exercise does not cause fatigue, } \\
\text { dyspnoea or undue palpitation }\end{array}$ & $\begin{array}{l}\text { Asymptomatic Left } \\
\text { Ventricular Dysfunction }\end{array}$ \\
\hline II & $\begin{array}{l}\text { Slight limitation of physical activity: } \\
\text { without symptoms at rest, normal physical } \\
\text { activity causes fatigue, palpitations or } \\
\text { dyspnoea. }\end{array}$ & Mild Heart Failure \\
\hline III & $\begin{array}{l}\text { Charged physical limitation: no symptoms } \\
\text { at rest, any physical activity causes the } \\
\text { appearance of symptoms }\end{array}$ & Moderate Heart Failure \\
\hline IV & $\begin{array}{l}\text { Inability to perform physical activity: the } \\
\text { symptoms of heart failure are present } \\
\text { even at rest and increase with any } \\
\text { physical activity }\end{array}$ & Severe Heart Failure \\
\hline
\end{tabular}

\section{Statistical analysis:}

We used SPSS 19.0 statistic software and we categorized the values using contingency tables utility and chi-square analysis for the significance on the changes before and after the treatment. Values of chi-square under 0,05 were considered significant.

\section{Results and Discussion}

The NYHA functional classification assesses the physical activity of the patient with $\mathrm{CHF}$, based on the subjective assessment made by the physician during the examination of the presence and severity of dyspnoea. This has an important prognostic value since it allows following the evolution and response to the treatment [9].

During ozone therapy, we observed that most of the patients were in class III for $66.7 \%$ of the patients before starting the treatment. At 45 days after the 15 sessions, a significant change was observed, with $86.7 \%$ cases in class II, results that remained in progress throughout the year under treatment until reaching $53.3 \%$ of them to class I. (Table 3 ).

This process suggests that the response of the organism to autohemotherapy with the doses used was favorable, although it is not able to eradicate the disease; it tends to significantly improve the functional limitations of HF, which agrees with similar studies [10].

The ejection fraction was assessed during different stages of our study (Table 4). Before starting treatment, most patients had an LVEF of 35-40 for $22.2 \%$, and $44.4 \%$ had a Fraction of Erection of $45-50$ per year, attributing the effects of ozone on the contractile function of the myocardium, which 
improves the metabolism of the cardiac muscle, increases the circulating serotonin and causes a cardioprotective effect already mentioned in previous studies [11,12].

Tabla 3. Behavior of the Functional Classification of HF in 45 patients treated with ozone therapy.

\begin{tabular}{lllll} 
CLASS & $\begin{array}{l}\text { Before starting } \\
\text { treatment }\end{array}$ & $\begin{array}{l}\mathbf{4 5} \text { days after completion } \\
\text { of treatment }\end{array}$ & $\mathbf{6}$ months & $\mathbf{1}$ year \\
\hline I & 0 & $6(13.3 \%)^{*}$ & $19(42.22 \%)^{*}$ & $24(53.3 \%)^{*}$ \\
II & $15(33.3 \%)$ & $39(86.7 \%)^{*}$ & $26(57.8 \%)^{*}$ & $21(46.7 \%)^{*}$ \\
III & $30(66.7 \%)$ & 0 & 0 & 0 \\
IV & 0 & 0 & 0 & 0
\end{tabular}

${ }^{*}$ chi-square significant value

Tabla 4. Eject Fraction Behavior in 45 patients treated with ozone therapy.

\begin{tabular}{lllll} 
FEVI & $\begin{array}{l}\text { Before starting } \\
\text { treatment }\end{array}$ & $\begin{array}{l}\text { 45 days after completion } \\
\text { of treatment }\end{array}$ & $\mathbf{6}$ months & 1 year \\
\hline $30-35$ & $11(24.5 \%)$ & $6(13.3 \%)^{*}$ & 0 & 0 \\
$35-40$ & $19(42.2 \%)$ & $13(28.9 \%)^{*}$ & $13(28.9 \%)^{*}$ & $2(4.4 \%)^{*}$ \\
$40-45$ & $10(22.2 \%)$ & $15(33.3 \%)^{*}$ & $14(31.1 \%)^{*}$ & $17(37.9 \%)^{*}$ \\
$45-50$ & $5(11.1 \%)$ & $7(15.6 \%)^{*}$ & $12(26.7 \%)^{*}$ & $20(44.4 \%)^{*}$ \\
$>50$ & & $4(8.9 \%)^{*}$ & $6(13.3 \%)^{*}$ & $6(13.3 \%)^{*}$ \\
\hline
\end{tabular}

${ }^{*}$ chi-square significant value

\section{Conclusions}

This study strongly suggests that the application of major autohemoterapy produced a clinical and functional improvement in patients with CHF, evidencing its effectiveness as adjuvant therapy.

\section{References}

1. Krumholz HM, Chen YT, Wang Y, Vaccarino V, Radford MJ, Horwitz RI. Predictors of readmission among elderly survivors of admission with heart failure. Am Heart J. 2000;139(1):72-77.

2. Cowie MR. Annotated references in epidemiology. Eur J Heart Fail. 1999;1:101-107.

3. Ho KK, Pinsky JL, Kannel WB, Levy D. The epidemiology of heart failure: the Framingham Study. J Am Coll Cardiol. 1993;22(4 Supl A):6-13.

4. McKee PA, Castelli WP, McNamara PM, Kannel WB. The natural history 
of congestive heart failure: The Framingham study. $\mathrm{N}$ Engl $\mathrm{J}$ Med. 1971;285:1441-1446.

5. Damasceno A, Cotter G, Dzudie A, Sliwa K, Mayosi BM. Heart Failure in Sub-Saharan Africa: Time for Action. J Am Coll Cardiol. 2007;50(17): 1688-1693. doi: 10.1016/j.jacc.2007.07.030.

6. Cleland JGF, Gemmel I, Khand A, Boddy A. Is the prognosis of heart failure improving?. Eur J HeartFail. 1999;1(3):229-241.

7. Travagli V, Zanardi I, Bernini P, Nepi S, Tenori L, Bocci V. Effects of ozone blood treatment on the metabolite profile of human blood. Int $\mathrm{J}$ Toxicol. 2010 Mar;29(2):165-174. doi: 10.1177/1091581809360069.

8. Re L. Mawsouf MN, Menéndez S, León OS, Sánchez GM, Hernández F. Ozone Therapy: Clinical and basic evidences of its therapeutic potential. Arch Med Res. 2008;39:17-26. doi: 10.1016/j.arcmed.2007.07.005.

9. Hurst JW, Morris DC, Alexander RW. The use of the New York Heart Association's classification of cardiovascular disease as part of the patient's complete Problem List. Clin Cardiol. 1999;22(6):385-390.

10. Borroto-Rodríguez V, Suárez-Fleitas LR, Bocci V, Luisa B, LimaHernández LB, Cámbara-Peña $R$, et al. Ozonoterapia en la Insuficiencia Cardiaca Crónica [Ozonetherapy in chronic heart failure]. Revista Española de Ozonoterapia. 2016;6(1):9-26.

11. Merin O, Attias E, Elstein D, Schwalb H, Bitran D, Zimran A, et al. Ozone administration reduces reperfusion injury in an isolated rat heart model. $J$ Card Surg. 2007;22(4):339-342. doi: 10.1111/j.1540-8191.2007.00419.x.

12. Barackat SAE, Saleh NKM, Thabet SS, Salej HA, Fayez MA. Effect of medical ozone therapy on diabetes-induced cardiac dysfunction. JASMR. 2008;3:167-175. 